\title{
O CAPITALISMO NO QUADRO ESCRAVISTA DOS EUA E A MODERNIDADE INDUSTRIAL
}

(1DFernanda Novaes ${ }^{1}$

Resenha de: BAPTIST, Edward E. A metade que nunca foi contada: a escravidão e a construção do capitalismo norte-americano. São Paulo: Paz e Terra, 2019.

$\mathrm{N}$ ão há dúvidas de que a escravidão moderna tornou-se um tema clássico dos debates historiográficos, sobre o qual foram produzidos um sem-número de obras, e que atualmente segue como tema de dissenso de livros, teses e pesquisas. $\mathrm{O}$ que é incomum em A metade que nunca foi contada, do norte-americano Edward Baptist, são os debates que este livro gerou para além da esfera acadêmica. Lançado em 2014 nos Estados Unidos, um ano depois da estreia do filme 12 Anos de Escravidão, a obra recebeu uma resenha negativa no jornal The Economist, por não ser uma "história objetiva", ou científica o suficiente, pois caracterizava senhores de escravos sulistas do século XIX - e outros brancos que lucraram com a escravidão nesse período - como "vilões", e os negros como "vítimas". A resenha gerou tamanha polêmica que fez o jornal publicar uma nota de desculpas em uma tentativa de retratação. No entanto, esse foi apenas o epicentro de uma série de debates subsequentes que levaram Baptist e sua obra ao centro das atenções nas discussões sobre

I Universidade Federal Fluminense. Niterói - Rio de Janeiro - Brasil. 
o escravismo estadunidense. Não por acaso: o formato escolhido por Baptist para a construção de seu argumento gerou debates historiográficos, os quais comentarei mais adiante, e também atingiu noções consolidadas da memória nacional dos Estados Unidos, assim como da memória sobre a expansão do capitalismo industrial.

Utilizando como fio condutor relatos biográficos de pessoas escravizadas, e cruzando estes relatos com uma variedade de fontes e dados (como cadernos de contabilidade, jornais, debates parlamentares e dados quantitativos mais amplos), Baptist constrói uma narrativa sobre o fenômeno do acirramento da escravidão produtora de algodão no sul nos Estados Unidos após sua independência. Esse acirramento caracteriza um novo tipo de escravidão, uma segunda escravidão ${ }^{2}$, moldada para a extração exitosa de excedentes cada vez maiores desse trabalho, que por sua vez, argumenta Baptist, tiveram um papel central na expansão territorial do país, em seu desenvolvimento e no fortalecimento de investimentos e lucros. Em um escopo mais amplo, a nova forma de escravidão algodoeira foi também um pilar fundamental para o surgimento do complexo industrial têxtil da Inglaterra.

A escolha por enfatizar relatos biográficos expõe uma face dura da produção exponencial de algodão oitocentista: as técnicas de tortura, o desmembramento de relações familiares em migrações forçadas e a transfiguração de pessoas negras em mercadorias foram métodos integrantes do desenvolvimento econômico e do progresso da nação das liberdades individuais. Tais relatos se assemelham à narrativa do filme 12 Anos de Escravidão, baseado nas memórias de Solomon Northup, homem livre que foi sequestrado para trabalhar como escravo na Luisiana, cuja história também é citada na obra de Baptist. O livro adentra linhas teóricas e temas clássicos da história econômica, como trabalho e capitalismo, com recursos da história oral e

2 O autor faz menção ao conceito de Segunda Escravidão, de Dale Tomich, sem se aprofundar no mérito de suas premissas teóricas. No entanto, a influência do trabalho de Tomich se faz presente no livro. TOMICH, Dale. Through the prism of slavery: labor, capital, and world economy. New York: Lanham, Rowman \& Littlefield, 2004. 
debates sobre temas socialmente vivos ${ }^{3}$, como relações raciais e de gênero. Torna-se evidente também a habilidade do autor em trabalhar com a esfera das relações políticas intrincadas, as disputas e pactos entre grupos políticos do norte e do sul dos Estados Unidos. É provável que a opção do autor por esse formato científico-narrativo, junto ao conteúdo chocante dos relatos de escravizados, tenham suscitado a acusação de falta de objetividade por parte da resenha do The Economist. Ou talvez, a crítica tenha partido da ideia de que eventos tão significativos na trajetória do capitalismo, como o desenvolvimento dos Estados Unidos e a Revolução Industrial, só se concretizaram por meio da acumulação gerada pela crueldade do trabalho escravo. Essa ideia, no entanto, não pode ser vista como alheia ao âmbito científico, constituindo um tema de extensos debates acadêmicos.

Existe um argumento central em A metade que nunca foi contada: a relação simbiótica entre a exploração dos corpos negros - e as formas de tortura desenvolvidas para tal - e a ascensão do capitalismo estadunidense de fins do século XVIII até a Guerra Civil, na segunda metade dos oitocentos. Tal argumento implica em dois pontos a serem analisados à luz da produção científica sobre o tema. O primeiro, no nível nacional, diz respeito ao papel do escravismo sulista na expansão do território e no desenvolvimento econômico do país como um todo. O segundo ponto é a relevância deste escravismo para a expansão industrial inglesa, seguido da pergunta: esta escravidão é capitalista? Tais questões colocam o livro de Baptist no âmbito da chamada Nova História do Capitalismo (NHC), que propõe a revisão dos padrões da história do capitalismo a partir das relações políticas e das experiências dos grupos subalternizados. Outros trabalhos semelhantes da NHC, lançados na mesma época, são Empire of cotton de Sven Beckert (2014) e River of dark dreams de Walter Johnson (2013). ${ }^{4}$

3 O termo faz alusão ao conceito de "questões socialmente vivas", relativo a temas relevantes socialmente, assim como no campo de estudo historiográfico. LEGARDEZ, Alain; SIMONNEAUX, Laurence. L'école à l'épreuve de l'actualité: enseigner les questions vives. Paris: ESF, 2006.

4 BECKERT, Sven. Empire of cotton: a global history. New York: Alfred A. Knopf, 2014; JOHNSON, Walter. River of dark dreams: slavery and empire in the cotton kingdom. Cambridge: Harvard Univer- 
Estes três livros foram, por vezes, criticados conjuntamente, por partirem de premissas semelhantes e por terem construído o campo em torno da tríade algodão-escravidão-capitalismo. A maior parte das críticas ao campo atinge um ponto em comum: influenciados pelo trabalho de Eric Williams, bem como pelas reinterpretações de Kenneth Pomeranz e Joseph Inikori, os trabalhos da NHC, especialmente A metade que nunca foi contada, teriam ignorado os argumentos da Nova História Econômica baseados em estudos cliométricos e dados empíricos. ${ }^{5}$

As críticas de Alan Olmstead e Paul Rhode aos aspectos empíricos do livro são das mais extensas. ${ }^{6}$ Baptist cita a afirmação de Olmstead e Rhode sobre a quadruplicação da produtividade das fazendas de algodão entre 1800 e 1860, porém invalida a importância da inovação biológica das novas sementes nesse aumento, argumento central dos autores. A calibragem da violência por meio de um sistema de cotas crescentes, que punia escravos por não manterem seu ritmo de colheita, seria o principal motivo da produtividade crescente. $O$ papel da violência foi questionado não apenas por Olmstead e Rhode, mas também por James Oakes, que afirma que Baptist generaliza um cotidiano de torturas que não corresponde à realidade, mas nem por isso as relações do escravismo foram menos cruéis. ${ }^{7}$

Baptist teria também negligenciado que a tese da centralidade do algodão já estava presente no trabalho de Douglass North, e que a Nova História Econômica (NHE) já teria apresentado argumentos

sity Press, 2013.

5 Referência a tese sobre a centralidade do escravismo para a industrialização britânica em WILLIAMS, Eric. Capitalismo e escravidão. São Paulo: Companhia das Letras, 2012; e suas atualizações em POMERANZ, Kenneth. The great divergence: China, Europe, and the making of the Modern world economy. Princeton: Princeton University Press, 2000; e INIKORI, Joseph. Africans and the Industrial Revolution in England: a study in international trade and economic development. Cambridge: Cambridge University Press, 2002.

6 OLMSTEAD, Alan; RHODE, Paul. “Cotton, slavery, and the New History of Capitalism”. Explorations in Economic History, v. 67, jan. 2018, pp. 1-17.

7 OAKES, James. "Capitalism and slavery and the Civil War". International Labor and Working-Class History, n. 89, mar.-jun. 2016, pp. 195-220. 
contrários: a baixa relevância das exportações de algodão para o PIB, a menor lucratividade em relação ao milho, entre outros. ${ }^{8}$ No geral, os números de que Baptist lança mão para sedimentar suas afirmações sobre a centralidade do algodão no desenvolvimento dos Estados Unidos são superdimensionados ou de origem incerta. Ainda que as críticas da cliometria não levem em consideração a complexidade política ou as relações sistêmicas do capitalismo, um engajamento maior com a produção historiográfica deste campo fortaleceria os argumentos do livro.

Um outro ponto de análise em A metade que nunca foi contada é o caráter capitalista da escravidão, especificamente da segunda escravidão do sul estadunidense. Em uma leitura mais tradicional de modos de produção, Eric Hilt questiona a existência de uma relação de dependência do norte em relação ao sul, e Oakes aponta para uma ambiguidade entre a escravidão e o trabalho livre, entre o atraso e a modernidade. ${ }^{9}$ Tal ambiguidade dentro das mesmas fronteiras, afirma Oakes, teria sido o próprio estopim da Guerra Civil. Já para John Clegg, a escravidão da qual Baptist fala é capitalista, mas em razão das motivações e mentalidade dos senhores (razões endógenas), e não pela vitalidade de sua produção para a industrialização. ${ }^{10}$

$\mathrm{Na}$ realidade, Baptist não se preocupa em definir o capitalismo, mas em mostrar o quanto a escravidão foi necessária para o seu desenvolvimento. Ainda que primordialmente sua leitura seja delimitada por um Estado-nação, é importante levar em consideração a relação subjacente do escravismo algodoeiro com a Revolução Industrial. Gavin Wright aponta que, no período pré-Guerra Civil, as exportações do algodão sulista foram de grande importância para alimentar a indústria têxtil britânica, mas após a abolição tal demanda foi atendida por exportações da Índia, Egito e Brasil e, posteriormente,

8 OLMSTEAD, Alan; RHODE, Paul, op. cit.

9 OAKES, James, op. cit.; HILT, Eric. "Economic history, historical analysis, and the 'New History of Capitalism”'. The Journal of Economic History, v. 77, n. 2, jun. 2017, pp. 511-536.

10 CLEGG, John. “Capitalism and slavery”. Critical Historical Studies, set.-dez. 2015, pp. 281-304. 
pela produção do trabalho livre estadunidense. Wright afirma que a relevância da escravidão foi caindo no quadro do capitalismo global, aproximando-se da segunda tese de Williams. ${ }^{11}$ Isto significa que a perspectiva de causalidade entre escravidão e Revolução Industrial é frágil. Nas palavras de Dale Tomich: “Essa 'segunda escravidão' se desenvolveu não como uma premissa histórica do capital produtivo, mas pressupondo sua existência como condição para sua reprodução"12. Aqui surge outra questão: se a escravidão foi relevante, mas findou não por ambiguidades internas, e sim porque perdeu espaço no quadro mais amplo do capital, como ocorreu essa virada?

Algo que tanto Baptist quanto seus críticos podem considerar para responder esta e outras questões é a literatura da segunda escravidão brasileira, além dos trabalhos que se centram na presença imperial britânica na Índia e no comércio oriental. Oakes questiona se as plantations de algodão seriam o melhor lugar para analisar o capitalismo; mas se apenas analisarmos o capitalismo oitocentista em condições "ideais", nitidamente lucrativas, explicitamente modernizantes e criadoras de tecnologia, não há espaço para entendermos as desigualdades produzidas pelo sistema em nível global. Para Baptist, a segunda escravidão nos Estados Unidos é um fenômeno observado no âmbito nacional e referente à demanda inglesa. Mas se considerarmos os estudos da Segunda Escravidão de Rafael Marquese e Tâmis Parron, o fenômeno da escravidão oitocentista não pode ser compreendido apenas nos Estados Unidos: sua integração com os escravismos cubano e brasileiro formam uma unidade, uma nova divisão do trabalho. Consequentemente, a íntima relação entre o escravismo norte-americano e o escravismo cafeeiro brasileiro moldou preços, gerou impactos recíprocos e formou alianças e conflitos que

11 WRIGHT, Gavin. "Slavery and Anglo-American capitalism revisited". In: EHS Annual Conference. Belfast, 2019. Disponível em <http://www.ehs.org.uk/multimedia/tawney-lecture-2019-slavery-and-anglo-american-capitalism-revisited $>$.

12 TOMICH, Dale. Through the prism of slavery: labor, capital, and world economy. New York: Lanham, Rowman \& Littlefield, 2004, p. 87. 
auxiliam a compreensão da abolição nos Estados Unidos. ${ }^{13}$ Tanto a questão do caráter capitalista da escravidão quanto a conjuntura do escravismo sulista ganham novas nuances a partir destes debates.

Em relação à empreitada britânica no Oriente, John Darwin afirma que o desenvolvimento do Império Britânico origina-se na diversidade de relações estabelecidas em diferentes regiões de influência e domínio. Em um quadro de pressões geopolíticas em que a Inglaterra não era hegemônica, a busca pela inserção no comércio com a Índia, China, a antiga Anatólia e o Cáucaso permitiram que o Império Britânico se consolidasse como o entreposto "do comércio do Novo Mundo com o Velho - assim como para o comércio transoceânico entre Europa e Ásia até a abertura do Canal de Suez em 1869"14. Assim, a expressividade do fornecimento de matéria-prima estadunidense para as indústrias inglesas deve ser colocada em perspectiva para pensarmos o êxito da Revolução Industrial, já que a presença do Império no Oriente reconfigura o papel dos Estados Unidos para os ingleses.

A importância da escravidão algodoeira do século XIX para a formação dos Estados Unidos e sua integração aos interesses do capitalismo industrial em expansão são pontos importantes trazidos por Baptist e, ainda que sejam necessários ajustes e considerações mais consistentes, sua tese não pode ser descartada tão facilmente. A força de seus argumentos não está apenas nas narrativas e no alcance de sua obra para além dos limites do público acadêmico. Sua exposição traz à tona as contradições de estudiosos liberais, que acreditavam que o fim da escravidão norte-americana era inevitável frente ao progresso, e expõe a falta de diálogo entre as esferas econômica e política

13 MARQUESE, Rafael Bivar de; PARRON, Tâmis. "Internacional escravista: a política da Segunda Escravidão”. Topoi, Rio de Janeiro, v. 12, n. 23, 2011, pp. 97-117; e MARQUESE, Rafael Bivar de. "Estados Unidos, Segunda Escravidão e a economia cafeeira do Império do Brasil". Almanack, Guarulhos, n. 5, 2013, pp. 51-60; PARRON, Tâmis. A escravidão na era da liberdade: Estados unidos, Brasile Cuba, 1787-1846. Tese. FFLCH-USP, 2015.

14 DARWIN, John. The Empire Project: the rise and fall of the British world-system, 1830-1970. Cambridge:

Cambridge University Press, 2009, p. 37. 
em estudos historiográficos prévios. A ampliação dos horizontes de sua obra para além do nacionalismo metodológico será um passo importante para revelar outras partes da história que ainda não foram contadas.

\section{Bibliografia}

BAPTIST, Edward E. A metade que nunca foi contada: a escravidão e a construção do capitalismo norte-americano. São Paulo: Paz e Terra, 2019.

BECKERT, Sven. Empire of cotton: a global history. New York: Alfred A. Knopf, 2014.

CLEGG, John. "Capitalism and slavery”. Critical Historical Studies, set.-dez. 2015, pp. 281-304.

DARWIN, John. The Empire Project: the rise and fall of the British world-system, 1830-1970. Cambridge: Cambridge University Press, 2009.

HILT, Eric. "Economic history, historical analysis, and the 'New History of Capitalism”". The Journal of Economic History, v. 77, n. 2, jun. 2017, pp. 511536.

INIKORI, Joseph. Africans and the Industrial Revolution in England: a study in international trade and economic development. Cambridge: Cambridge University Press, 2002.

JOHNSON, Walter. River of dark dreams: slavery and empire in the cotton kingdom. Cambridge: Harvard University Press, 2013.

LEGARDEZ, Alain; SIMONNEAUX, Laurence. L'école à l'épreuve de l'actualité: enseigner les questions vives. Paris: ESF, 2006.

MARQUESE, Rafael Bivar de. "Estados Unidos, Segunda Escravidão e a economia cafeeira do Império do Brasil”. Almanack, Guarulhos, n. 5, 2013, pp. 51-60.

MARQUESE, Rafael Bivar de; PARRON, Tâmis. "Internacional escravista: a política da Segunda Escravidão”. Topoi, Rio de Janeiro, v. 12, n. 23, 2011, pp. 97-117.

OAKES, James. "Capitalism and slavery and the Civil War". International Labor and Working-Class History, n. 89, mar.-jun. 2016, pp. 195-220. 
OLMSTEAD, Alan; RHODE, Paul. "Cotton, slavery, and the New History of Capitalism”. Explorations in Economic History, v. 67, jan. 2018, pp. 1-17.

PARRON, Tâmis Peixoto. A escravidão na era da liberdade: Estados unidos, Brasil e Cuba, 1787-1846. Tese. FFLCH-USP, 2015.

POMERANZ, Kenneth. The great divergence: China, Europe, and the making of the Modern world economy. Princeton: Princeton University Press, 2000.

TOMICH, Dale. Through the prism of slavery: labor, capital, and world economy. New York: Lanham, Rowman \& Littlefield, 2004.

WILLIAMS, Eric. Capitalismo e escravidão. São Paulo: Companhia das Letras, 2012.

WRIGHT, Gavin. "Slavery and Anglo-American capitalism revisited". In: EHS Annual Conference. Belfast, 2019. Disponível em <http://www.ehs. org.uk/multimedia/tawney-lecture-2019-slavery-and-anglo-american-capitalism-revisited>.

Recebido em: 01/11/2019 - Aprovado em: 10/11/2019 